\title{
Monitoramento da evolução do tratamento da ausência de consolidação da fratura: Papel da fosfatase alcalina e da ultrassonografia*
}

\section{Monitoring the Progress of Treatment in Fracture Non-Union: The Role of Alkaline Phosphatase and Ultrasonography}

\author{
Dhanji S. Chaudhary ${ }^{1}$ Jayur J. Solanki ${ }^{1}$ Tarun Verma ${ }^{1}$ Viswanath H. Chavali ${ }^{10}$ \\ ${ }^{1}$ Departamento de Ortopedia, Medical College Baroda e SSG \\ Hospital, Vadodara, Gujarat, Índia \\ Rev Bras Ortop 2021;56:796-803. \\ Endereço para correspondência Dr. Viswanath H. Chavali, M.S. \\ Orthopaedic Surgery, A109, Swami Residency, Near Airforce Station, \\ Makarpura Road, Vadodara, Gujarat, Índia \\ (e-mail: vhcindia@gmail.com).
}

\section{Resumo \\ Palavras-chave \\ - calo ósseo \\ - ultrassonografia \\ - fosfatase alcalina \\ Objetivo Avaliar o papel da concentração sérica de fosfatase alcalina (FA) e da ultrassonografia no monitoramento do progresso do tratamento da ausência de consolidação em fraturas diafisárias. \\ Métodos Este estudo de coorte observacional prospectivo incluiu pacientes adultos com fraturas diafisárias dos principais ossos longos previamente submetidas a fixação interna sem consolidação. Após o tratamento definitivo, os pacientes foram avaliados periodicamente por seis meses, com realização seriada de ultrassonografia, determi- nação da concentração de FA e radiografias para verificar a presença de consolidação. Resultados Após um aumento inicial em sete semanas, os níveis de FA voltaram ao valor normal em pacientes com fraturas consolidadas, mas continuaram elevados nos casos de ausência de consolidação. Da mesma forma, após uma elevação do índice de resistência (IR) vascular em cerca de 12 semanas em todos os pacientes, o IR diminuiu nos casos que progrediram para consolidação, mas continuou alto até as 24 semanas em fraturas não consolidadas. Os casos com ausência de consolidação ainda apresen- tavam calo hipoecogênico às 24 semanas, que não se converteu no calo hiperecogê- nico observado nos casos que progrediram para consolidação. \\ Conclusão Alterações significativas sugestivas de consolidação foram simultanea- mente observadas nas radiografias, na ultrassonografia e na concentração de FA durante o período de acompanhamento. No entanto, a realização seriada de exames da concentração de FA e de ultrassonografia durante o acompanhamento indicou o}

\footnotetext{
Estudo desenvolvido no Departamento de Ortopedia, Medical College Baroda e SSG Hospital, Vadodara, Gujarat, Índia.
}

recebido

15 de Julho de 2020

aceito

02 de Outubro de 2020
DOI https://doi.org/

10.1055/s-0041-1724072. ISSN 0102-3616.

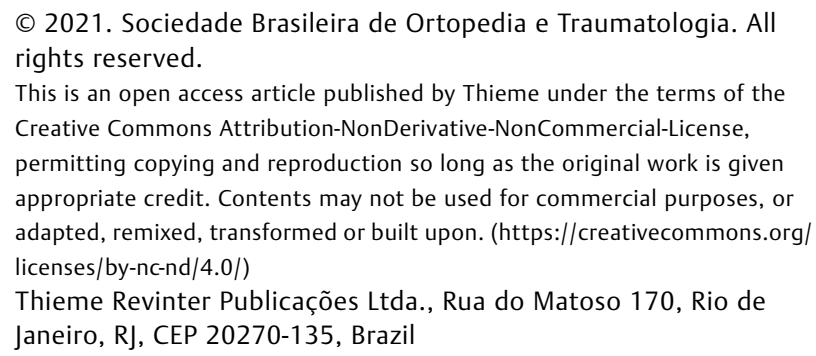

(c) 2021. Sociedade Brasileira de Ortopedia e Traumatologia. All rights reserved.

This is an open access article published by Thieme under the terms of the Creative Commons Attribution-NonDerivative-NonCommercial-License, permitting copying and reproduction so long as the original work is given appropriate credit. Contents may not be used for commercial purposes, or adapted, remixed, transformed or built upon. (https://creativecommons.org/ licenses/by-nc-nd/4.0/) Thieme Revinter Publicações Ltda., Rua do Matoso 170, Rio de Janeiro, RJ, CEP 20270-135, Brazil 


\begin{abstract}
Keywords

- bony callus

- ultrasonography

- alkaline phosphatase

Objective To evaluate the role of Serum Alkaline Phosphatase (ALP) and UltraSonoGraphy (USG) in monitoring the progress of treatment in diaphyseal non-unions.

Methods This prospective observational cohort study included adult patients with diaphyseal fractures of major long bones previously treated with internal fixation and eventually resulting in non-union. Following the definitive treatment for non-union, the patients were followed up periodically for six months and serial monitoring of the levels of ALP and USG were perrfomed along with radiographs (X-rays) to ascertain the status of the union.

Results After an initial rise at seven weeks, ALP levels declined to normal value in fractures which united, whereas they remained high in cases of persistent non-union. Similarly, after an elevation of the vascular resistive index (RI) at around 12 weeks in all the patients, it decreased in cases progressing to union, while it remained persistently high even at 24 weeks in fractures failing to unite. Cases of persistent non-union continued to show hypo-echogenic callus at 24 weeks instead of converting into hyperechogenic callus, as observed in cases which progressed to union.

Conclusion Significant changes suggestive of union appeared simultaneously on the X-rays, USG and ALP levels during the follow-up. However, serial examination of the ALP levels and USG during the follow-up gave a hint of the direction of progress in the healing process of fracture non-union. Their role in monitoring the outcome of nonunion is more complimentary than supplementary to the $\mathrm{X}$-rays
\end{abstract}

progresso da consolidação da fratura. Seu papel no monitoramento da ausência de consolidação é mais complementar do que suplementar à radiografia.

\section{Introdução}

A ausência de consolidação da fratura é um desfecho difícil de prever, e, embora seja uma complicação conhecida, é considerada um desfecho clínico ruim por médicos e pacientes. ${ }^{1} \mathrm{~A}$ avaliação clínica do estado de consolidação de fraturas é variável, e não há consenso quanto à confiabilidade dos vários métodos de determinação de seu progresso. A observação clínica é combinada à avaliação radiográfica para a análise de fraturas agudas e sem consolidação, embora outros métodos de monitoramento e documentação da cicatrização óssea, como tomografia computadorizada (TC), ressonância magnética e cintilografia óssea, tenham sido usados com moderação em alguns casos. No entanto, além da preocupação com a disponibilidade desses recursos, tais métodos avançados representam um maior custo financeiro e/ou risco de radiação para o paciente. $O$ objetivo deste estudo foi avaliar o papel de métodos alternativos de investigação, a concentração sérica de fosfatase alcalina (FA) e a ultrassonografia, e compará-los à radiografia convencional no acompanhamento da evolução do tratamento da ausência de consolidação diafisária. Além de terem custo baixo e alta disponibilidade, a FA e a ultrassonografia foram escolhidas para representar marcadores bioquímicos e físicos de consolidação, respectivamente.

\section{Metodologia}

Este estudo observacional prospectivo foi realizado em um hospital público terciário vinculado a uma instituição de ensino de pós-graduação entre abril de 2018 e setembro de 2019, com a devida autorização do Comitê de Ética institucional. Fraturas diafisárias dos ossos longos, ou seja, fêmur, tíbia (acompanhada ou não pela fíbula), úmero e rádio e/ou ulna previamente tratadas em adultos com qualquer tipo de fixação interna (> 18 anos) sem consolidação foram incluídas no estudo. Apenas os pacientes com função hepática normal confirmada por ultrassonografia e por exames bioquímicos séricos participaram do estudo. 0 tratamento da ausência de consolidação permaneceu independente do estudo. Todos os pacientes foram acompanhados por seis meses em intervalos de seis semanas. Em cada acompanhamento, todos os pacientes foram submetidos a avaliação clínica e radiográfica simples para a detecção de sinais de consolidação. Além disso, a concentração de FA foi determinada, e as fraturas foram avaliadas por ultrassonografia quanto à ecogenicidade e ao índice de resistência (IR) vascular do calo. A determinação de FA foi feita por espectrofotometria, utilizando o método cinético da International Federation of Clinical Chemistry (IFCC) com p-nitrofenilfosfato (pNFF); o intervalo de referência do laboratório era de $28 \mathrm{UI} / \mathrm{L}$ a $111 \mathrm{UI} / \mathrm{L}$. A ultrassonografia foi realizada com câmera Philips iU22 (Amsterdã, Holanda) equipada com transdutor linear com resolução de $12 \mathrm{MHz}$ a $5 \mathrm{MHz}$, programa MSK Superficial e Doppler colorido tridimensional. Os autores avaliaram a consolidação da fratura com radiografias simples, mas o exame ultrassonográfico da lesão foi realizado por um radiologista independente, sem conhecimento dos achados radiográficos. A - Fig. 1 mostra uma breve visão geral da metodologia. 


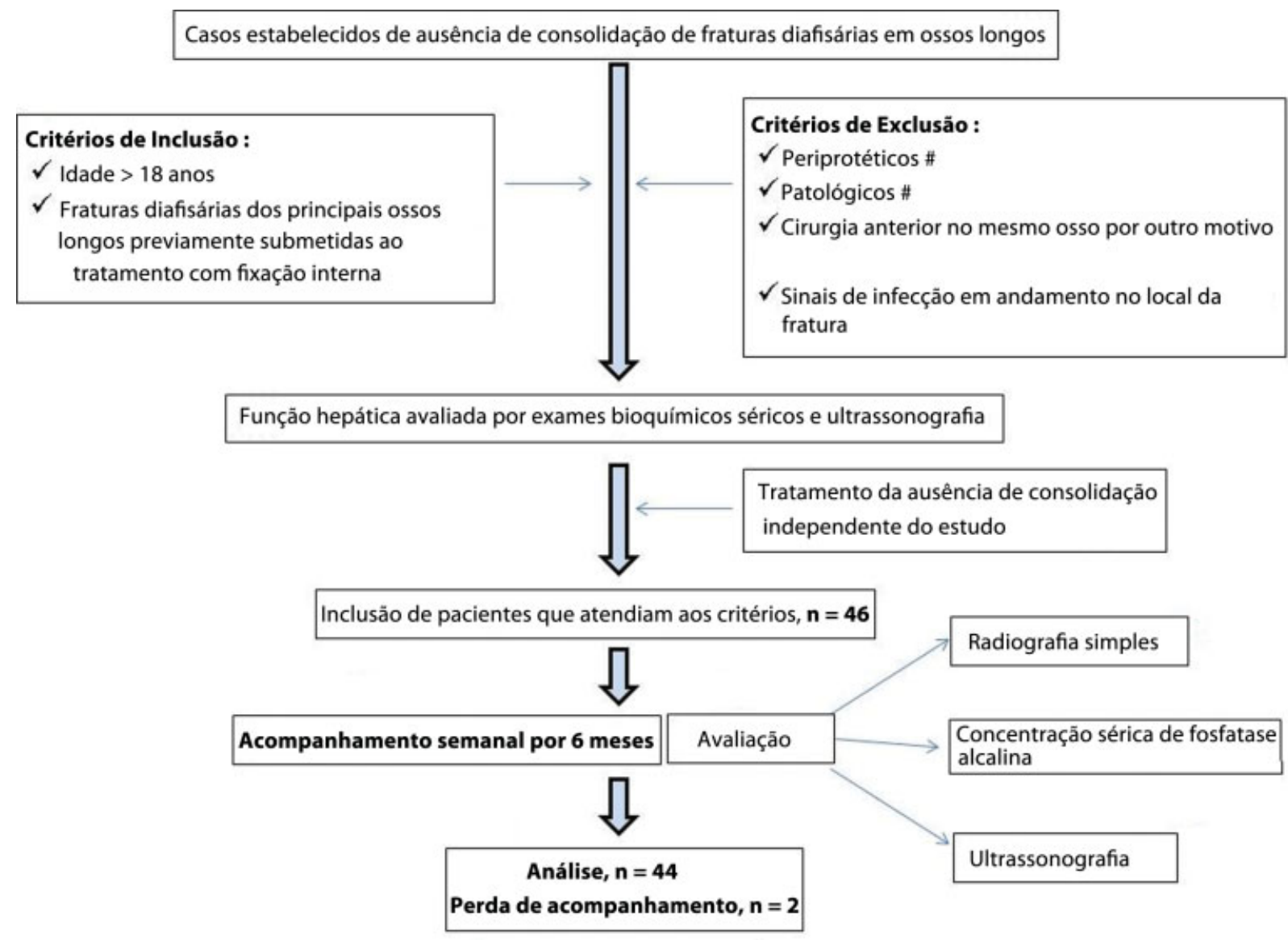

Fig. 1 Fluxograma da metodologia básica.

\section{Observações e Resultados}

No total, 44 pacientes (36 homens e 8 mulheres) foram acompanhados e analisados. Entre eles, havia 20 casos de ausência de consolidação em fraturas diafisárias em membros superiores, e 24 casos em membros inferiores. Morfologicamente, 24 casos eram de atrofia, 6, de hipertrofia, e 14, de ausência de consolidação cominutiva. A idade média dos pacientes foi de 37 (gama: 18 a 75) anos. Ao todo, 28 pacientes foram submetidos a enxerto ósseo esponjoso/tricortical/fibular, seis passaram por outro procedimento de fixação, 4 foram submetidos a extração de implante seguida de órtese funcional, 4 foram tratados por dinamização tardia com haste bloqueada estática, e os outros 2 receberam um sistema de fixação de Ilizarov. A - Tabela 1 resume as observações do estudo. Casos ilustrativos são mostrados nas -Figs. 2, 3 e $\mathbf{4}$.

\section{Radiografias}

Consideramos uma fratura consolidada apenas quando as radiografias mostraram a formação de ponte óssea ao longo da lesão nas duas incidências ortogonais. Um total de 30 pacientes apresentaram sinais de consolidação, e 14 ainda apresentavam ausência de consolidação nas radiografias realizadas no último acompanhamento (-Figs. 2d, 3d e 4d). Calos foram observados entre 12 e 24 semanas. 0 tempo médio de consolidação radiográfica foi de 18,8 (gama: 12 a 24) semanas.
O enxerto ósseo $(n=22)$ teve os resultados mais promissores de consolidação.

\section{Concentração Sérica de Fosfatase Alcalina}

De modo geral, obervamos que pacientes com ausência de consolidação nos primeiros 6 meses após a cirurgia primária costumam ter concentrações de FA $>110$ UI/L. A concentração média de FA quando os pacientes foram recrutados foi de 120 (gama: 42 a 202) UI/L. O pico médio atingido durante o estudo foi de 180 (gama: 136 a 216) UI/L. A princípio, a concentração de FA aumentou em todos os casos, e atingiu um pico por volta das sete semanas. Nas fraturas que progrediram para consolidação, os níveis de FA voltaram ao normal no final do estudo. Nos casos de ausência de consolidação, a concentração FA continuou alta do primeiro pico até o final do estudo (-Fig. 5). Em casos com e sem consolidação, a concentração média de FA no final do estudo foi de $94 \mathrm{UI} / \mathrm{L}$ e $128 \mathrm{UI} / \mathrm{L}$, respectivamente

\section{Ultrassonografia}

A avaliação da consolidação das fraturas por ultrassonografia foi realizada qualitativamente, pela ecogenicidade do calo, e quantitativamente, por medição do IR. ${ }^{2}$

Entre nossos pacientes, havia casos estabelecidos de ausência de consolidação. Portanto, estruturas hipoecoicas (tecido fibroso) foram observadas desde o primeiro dia do 
Tabela 1 Resumo das observações referentes aos desfechos do estudo

\begin{tabular}{|c|c|c|c|}
\hline Desfecho $\rightarrow$ & Consolidação & Ausência de consolidação & Total/Bruto \\
\hline \multicolumn{4}{|l|}{ Parâmetros $\downarrow$} \\
\hline Número de casos & 30 & 14 & 44 \\
\hline \multicolumn{4}{|l|}{ Tipo de ausência de consolidação } \\
\hline Atrófica & 18 & 6 & 24 \\
\hline Hipertrófica & 4 & 2 & 6 \\
\hline Cominutiva & 8 & 6 & 14 \\
\hline \multicolumn{4}{|c|}{ Concentração média de fosfatase alcalina (28 a 111 UI/L) } \\
\hline À internação & 121 & 118 & 120 \\
\hline Ao final do acompanhamento & 94 & 128 & 105 \\
\hline Valor máximo durante o estudo & 179 & 181 & 180 \\
\hline \multicolumn{4}{|c|}{ Valor médio de índice de resistência vascular (ultrassonografia) } \\
\hline À internação & 0,28 & 0,12 & 0,22 \\
\hline Ao final do acompanhamento & 0,22 & 0,9 & 0,44 \\
\hline Valor máximo durante o estudo & 0,79 & 1,04 & 0,87 \\
\hline \multicolumn{4}{|l|}{ Tempo de acompanhamento (semanas) } \\
\hline Pico do nível de fosfatase alcalina & 7,2 & 6,9 & 7,0 \\
\hline Valor máximo do índice de resistência vascular & 14,4 & 21,4 & 16,6 \\
\hline Calo hiperecoico na ultrassonografia & 20 & Não observada & 20 \\
\hline Calo na radiografia (tempo de consolidação) & 18,8 & Não observada & 18,8 \\
\hline
\end{tabular}

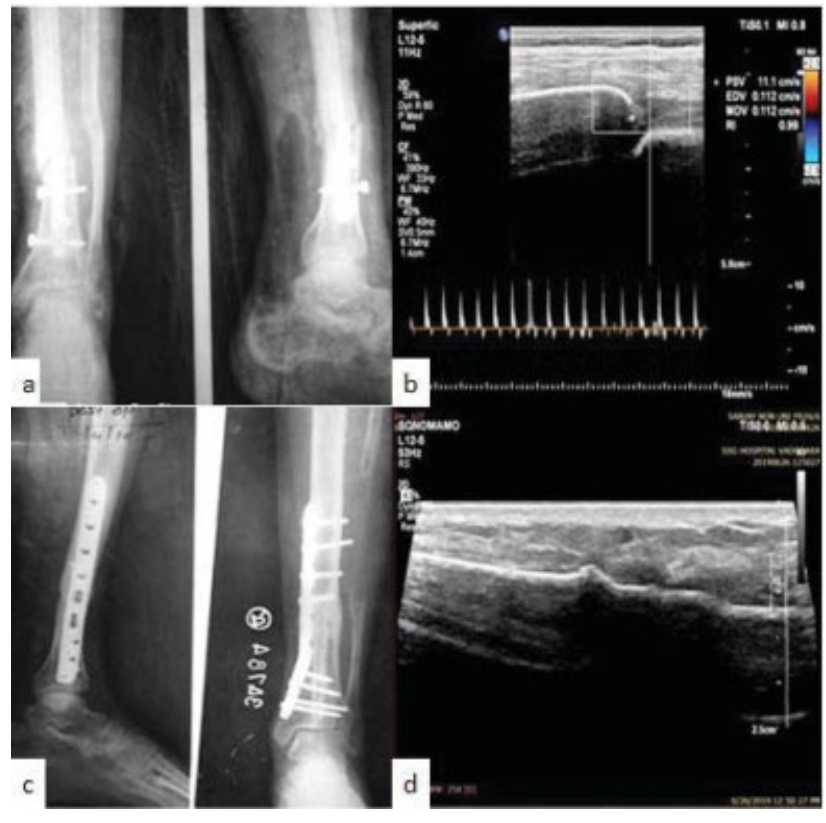

Fig. 2 Caso ilustrativo 1. (A) A radiografia mostra a ausência de consolidação da tíbia distal. (B) A ultrassonografia mostra o defeito ósseo com alto índice de resistência. (C) Consolidação da fratura 24 semanas após o enxerto ósseo. (D) A ultrassonografia em 24 semanas mostra sinais hiperecoicos e ausência de resistência vascular.

estudo. No entanto, diferentemente dos sinais hipoecoicos homogêneos de um hematoma recém-formado que se converte em calo mole, a ultrassonografia em escala de cinza realizada no recrutamento mostrou, em nossos casos, hipoe-

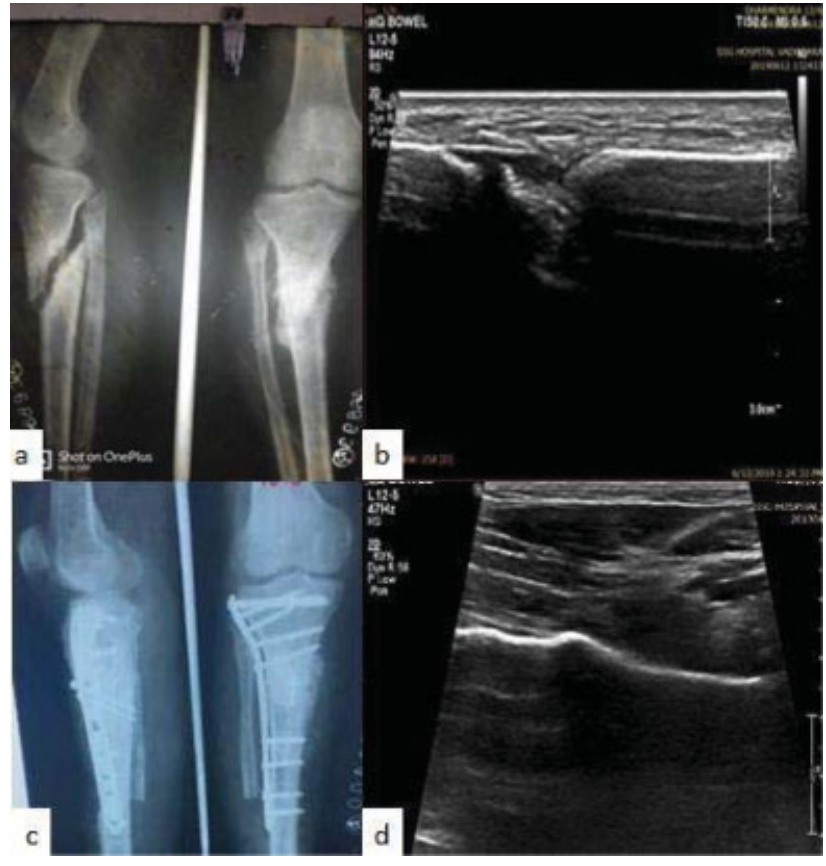

Fig. 3 Caso ilustrativo 2. (A) A radiografia mostra a ausência de consolidação da tíbia proximal. (B) A ultrassonografia mostra sinais hipoecoicos heterogêneos de ausência de consolidação. (C) Consolidação da fratura 18 semanas após o enxerto ósseo. (D) A ultrassonografia em 18 semanas mostra sinais hiperecoicos.

cogenicidade heterogênea devido à fibroesclerose que se seguiu na ausência de consolidação ( - Figs. 2b, 3b e $\mathbf{4 b}$ ). 0 tempo médio necessário para o aparecimento de calos hiperecogênicos sugestivos de mineralização nas fraturas 


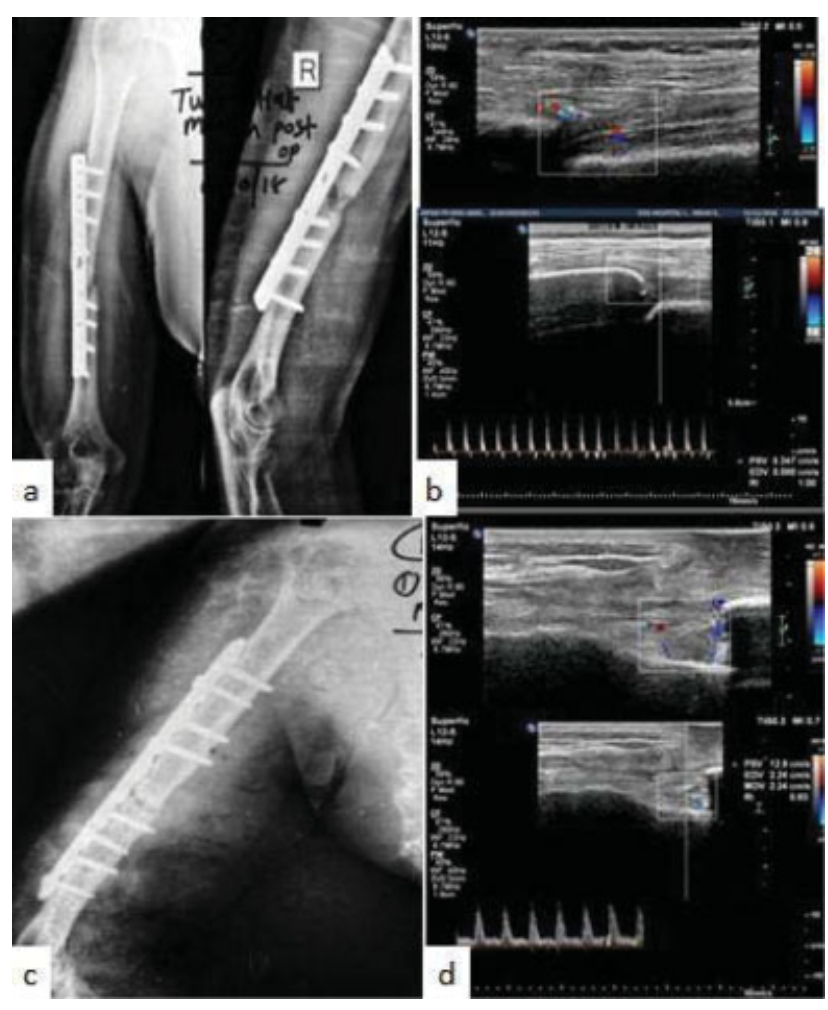

Fig. 4 Caso ilustrativo 3. (A) A radiografia mostra a diáfise umeral não consolidada. (B) A ultrassonografia mostra o defeito ósseo com alto índice de resistência. (C) Ausência de consolidação da fratura 24 semanas após a cirurgia de revisão. (D) A ultrassonografia em 24 semanas mostra o defeito ósseo, os sinais hipoecoicos, e a alta resistência vascular. com consolidação foi de 20 (gama: 18 a 24) semanas. Nos casos sem consolidação, o ultrassom continuou a mostrar hipoecogenicidade em 24 semanas (-Fig. 4d).

O IR médio ao recrutamento no estudo foi de 0,22 ; em 30 pacientes, o não foi possível registrar o IR devido à fibroesclerose. Independentemente do resultado, uma elevação constante no IR foi observada em todos os casos até cerca de 12 a 18 semanas. A seguir, o IR diminuiu em pacientes que progrediram para a consolidação. Em fraturas não consolidadas, o IR continuou elevado até as 24 semanas (-Fig. 6). O IR médio na última avaliação de acompanhamento foi de 0,22 e 0,90 , em casos com e sem consolidação, respectivamente (-Fig. 2d, 3d e 4d).

Os achados do estudo foram submetidos a uma análise bruta ( - Tabela 2 ) que usou a frequência com que todos os parâmetros, ou seja, radiografia, FA, calo hiperecoico e IR, apresentaram sinais positivos de consolidação em diferentes tempos durante o acompanhamento. Calos em ponte na radiografia, níveis de FA dentro da faixa de referência do laboratório, sinais hiperecoicos na ultrassonografia em escala de cinza, e IR inferior ao valor anterior obtido por Doppler ultrassonográfico foram considerados sinais indicativos de consolidação. Nessa análise, os parâmetros foram mutuamente inclusivos para aquele ponto do acompanhamento. O primeiro período em que os níveis de FA e a ultrassonografia previram um possível resultado do tratamento (12 a 18 semanas) coincidiu com as primeiras mudanças observadas nas radiografias.

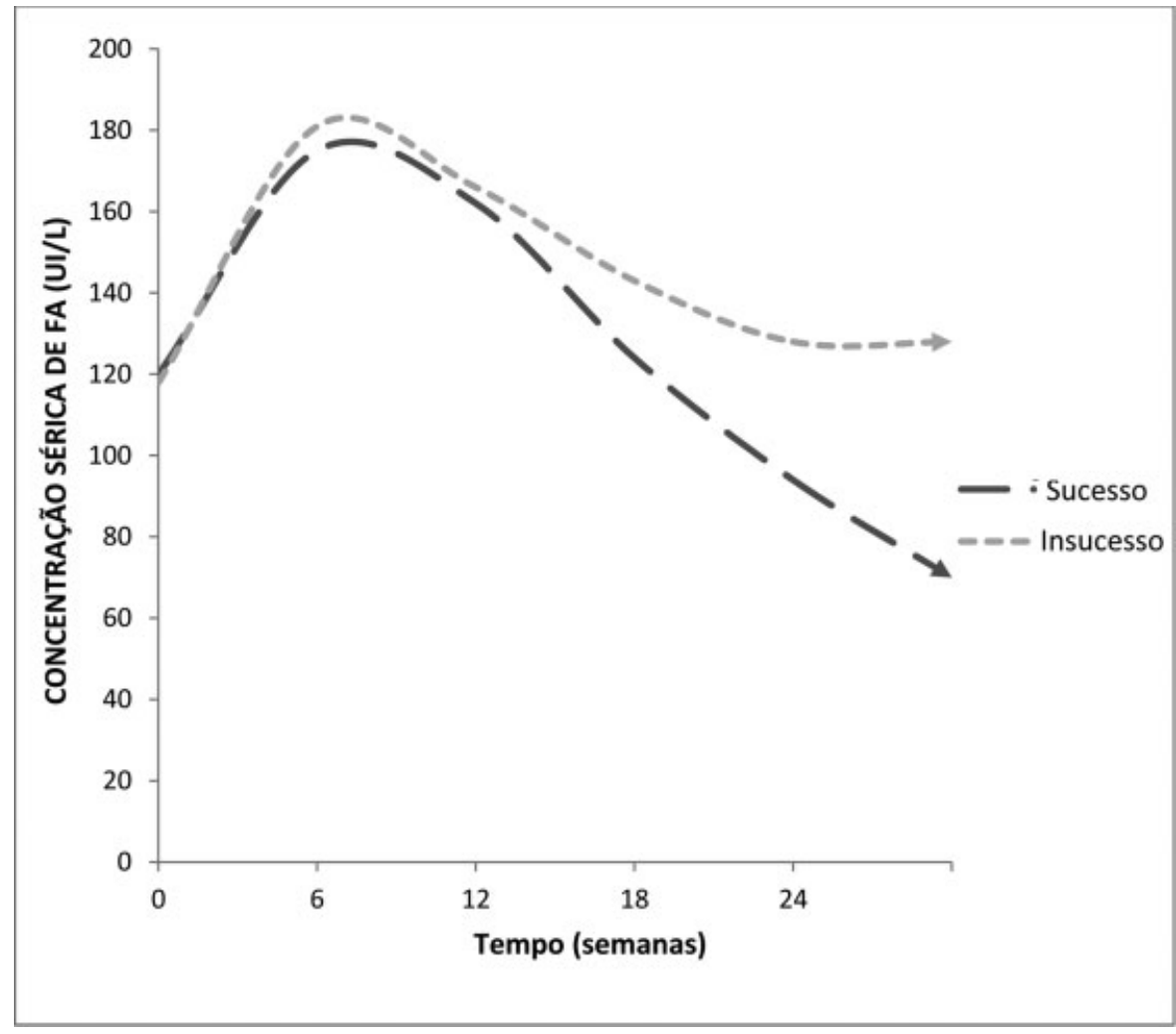

Fig. 5 Tendência da concentração sérica média de fosfatase alcalina (FA) na presença ou ausência de consolidação. 


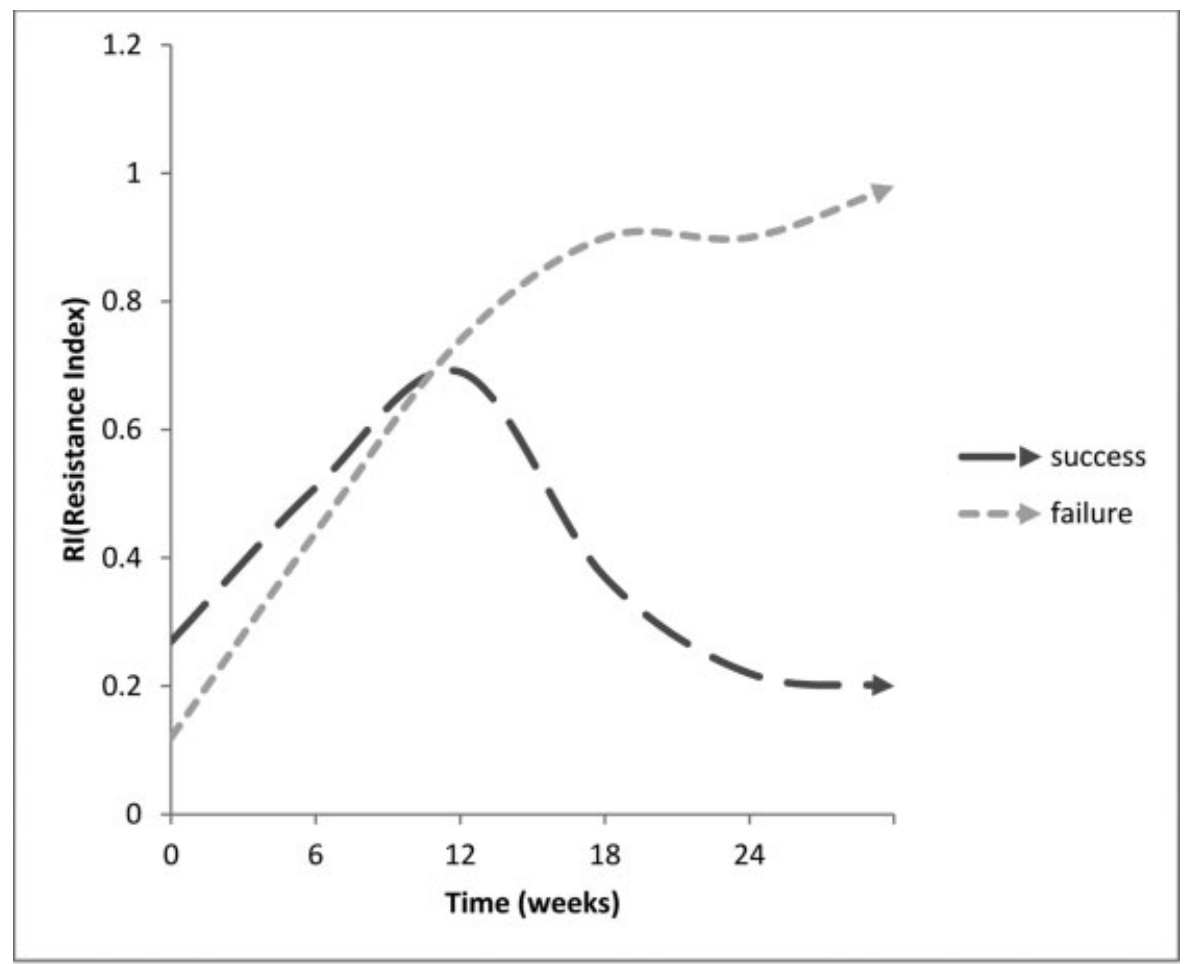

Fig. 6 Tendência do índice de resistência vascular médio na presença ou ausência de consolidação.

Tabela 2 Análise dos achados do estudo

\begin{tabular}{|l|l|l|l|l|}
\hline Investigação & Número de pacientes & $\mathbf{1 8}$ semanas & $\mathbf{2 4}$ semanas \\
\cline { 2 - 5 } & $\mathbf{6}$ semanas & $\mathbf{1 2}$ semanas & $\mathbf{2 2}$ & 30 \\
\hline Radiografia (formação de calo ósseo) & 0 & 4 & 8 & 30 \\
\hline Fosfatase alcalina (<111 UI/L) & 0 & 0 & 20 & 30 \\
\hline $\begin{array}{l}\text { Ultrassonografia (sinal hiperecoico + diminuição } \\
\text { do índice de resistência vascular) }\end{array}$ & 0 & 0 & & \\
\hline
\end{tabular}

\section{Discussão}

As fraturas diafisárias não consolidadas em ossos longos, apesar da baixa incidência, representam uma tarefa difícil para o cirurgião responsável pelo tratamento. Embora haja muitas informações na literatura a respeito da ausência de consolidação, não encontramos nenhum estudo similar que descrevesse o monitoramento da evolução de seu tratamento em ossos longos. Zimmermann et al. ${ }^{3}$ avaliaram de maneira detalhada os estudos sobre exames laboratoriais e de imagem na ausência de consolidação de ossos longos em animais. No entanto, a maioria deles parece pouco passível de reprodução na prática clínica rotineira. A melhora clínica, indicada por sustentação de peso sem dor, uso do membro acometido e resolução do edema e da sensibilidade, sempre confortaram o paciente e o cirurgião, pois são um reflexo de um progresso razoável. Evidências radiológicas de apoio, na forma de radiografias e TCs, reforçaram essas impressões clínicas. A avaliação qualitativa inclui o traço da fratura, suas margens e o defeito ósseo, o calo externo, a razão entre o calo e o córtex, e o calo em ponte. Métodos diagnósticos avançados, como densitometria óssea, TC multidirecional e exames de laboratório, como os dos fosfatos alcalinos específicos de ossos, metaloproteases de matriz, e determinados fatores de crescimento, ${ }^{4}$ são mencionados em teoria, mas ainda não são clinicamente utilizados de forma rotineira.

Diversos estudos ${ }^{5-8}$ publicados indicam que a concentração de FA pode ser usada como um complemento às evidências clínicas e radiológicas de cicatrização. Em estudos clínicos, a concentração basal de FA foi significativamente maior, e houve tendência a um aumento tardio durante os primeiros dois meses de consolidação em fraturas agudas; assim, ela pode ajudar a prever o retardo na consolidação. ${ }^{9,10}$ Acredita-se que este aumento na atividade de FA se deva ao aumento da concentração de sua isoenzima óssea durante o processo de cicatrização, ${ }^{11}$ e coincide com o início da mineralização. ${ }^{12}$ Em consonância com os estudos de marcadores biológicos nas fraturas agudas, observamos um aumento temporário na concentração de FA até sete semanas após a intervenção em todos os pacientes, seguido da normalização dos níveis naquelas com sinais de consolidação. Acreditamos que, como nas fraturas agudas, a medição seriada dos níveis de FA também é importante no monitoramento do tratamento de fraturas não consolidadas. 
A avaliação do calo por ultrassonografia foi bem descrita na literatura, e é observada bem mais cedo do que em radiografias simples. ${ }^{13-16}$ Alterações significativas na composição mineral do calo durante a consolidação da fratura mudam a velocidade da onda refletida (eco) captada pelos transdutores. Com base neste padrão de eco, o calo é considerado hipoecoico ou hiperecoico. ${ }^{17} \mathrm{O}$ calo em início de desenvolvimento (macio) das fraturas recentes é hipoecoico e homogêneo, e a mineralização provoca seu amadurecimento, tornando-o um calo hiperecoico e homogêneo (duro) com o passar do tempo. A presença de um sinal ultrassonográfico hiperecoico no local da fratura esteve $100 \%$ correlacionado à presença de calo duro nas biópsias. ${ }^{14}$ As fraturas sem consolidação progressiva apresentam persistência do padrão hipoecoico. O tecido fibroso é visto como uma estrutura hipoecoica heterogênea na ausência de consolidação. ${ }^{12}$ Chachan et al. ${ }^{18}$ compararam a eficácia da radiografia simples e da ultrassonografia no monitoramento da consolidação da fratura, e descobriram que a sensibilidade e a especificidade da ultrassonografia no diagnóstico da consolidação são de $100 \%$ e $80 \%$, respectivamente. No presente estudo, todos os pacientes apresentaram calo hipoecoico até 16 semanas, que se converteu em calo hiperecoico nos indivíduos com sinais de consolidação, e continuou hipoecoico naqueles sem consolidação. Na ausência de consolidação, o tecido fibroesclerótico foi um fator limitante significativo na avaliação qualitativa do calo pela ultrassonografia no presente estudo. Em nossa amostra composta exclusivamente por casos de ausência de consolidação, a inexistência de uma reação perióstea induzida pelo hematoma e as imagens ecogênicas mistas devidas à paralisação do processo de cicatrização inicial podem ter sido os fatores que levaram à subestimação do começo da cicatrização diagnosticada pela ultrassonografia.
O processo de cicatrização da fratura pode ser acompanhado por Doppler colorido e análise espectral. ${ }^{19}$ A ultrassonografia pode acompanhar a formação de novos vasos no local da fratura e avaliar suas características de fluxo durante o desenvolvimento do calo. Além de acompanhar a formação de novos vasos no local da fratura, a ultrassonografia com Doppler pode determinar o IR, que reflete a resistência ao fluxo sanguíneo causada por um leito microvascular distal ao local da medição. Em pacientes com calo de desenvolvimento normal, o calibre dos vasos aferentes aumenta de forma progressiva ,e seu número diminui. O IR aumenta de maneira progressiva até valores semelhantes aos observados em vasos nutrícios $(0,36$ a 0,90$)$. No segundo mês após a fratura, uma túnica muscular se desenvolve na parede do vaso, que se converte em um vaso maduro com a mineralização progressiva do córtex, fazendo com que o IR gradualmente diminua até desaparecer. ${ }^{11}$ Por outro lado, os pacientes com ausência de consolidação e cicatrização retardada apresentam maior resistência devido à má formação da neovascularização e ao aumento da resistência periférica em vasos residuais por involução fibroesclerótica da consolidação óssea ${ }^{11}$ (graficamente representada na - Fig. 7). Em consonância com descrição anterior, neste estudo, o IR aumentou de forma constante até cerca de 12 semanas em todos os pacientes; depois, às 24 semanas, os pacientes que progrediram para consolidação apresentaram IR baixo, e aqueles que progrediram para ausência de consolidação apresentaram IR persistentemente alto.

A análise bruta dos achados deste estudo mostrou que as alterações na concentração de FA, na ultrassonografia e na radiografia foram simultâneas durante o acompanhamento do tratamento da ausência de consolidação da fratura. Nenhum desses parâmetros se mostrou superior

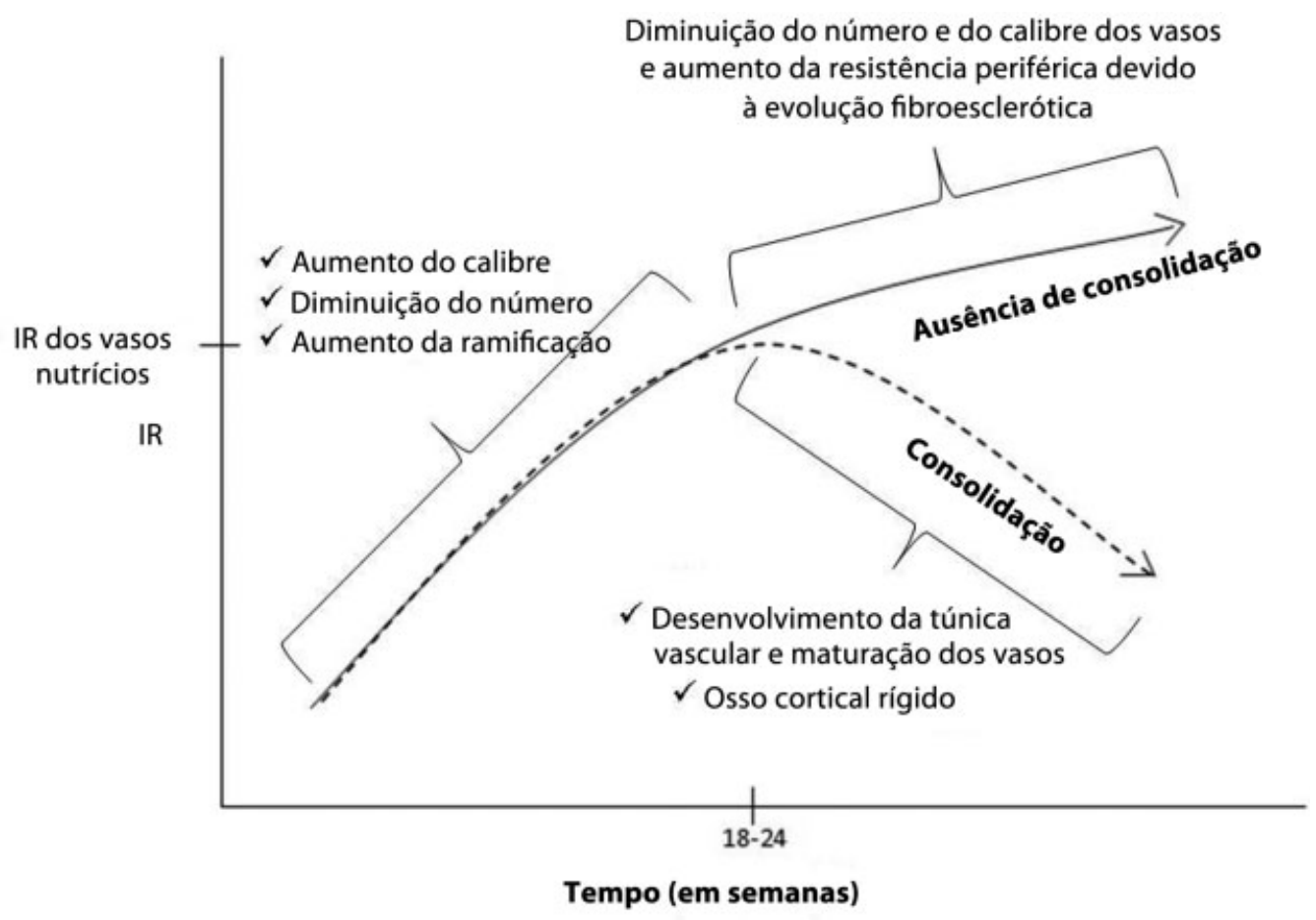

Fig. 7 Alterações vasculares e seus efeitos no índice de resistência vascular (IR) na presença ou ausência de consolidação. 
em termos de previsão do resultado do tratamento. No entanto, a determinação seriada dos níveis de FA e a ultrassonografia indicaram o progresso da consolidação da fratura. Muitas pesquisas científicas ainda são necessárias antes que marcadores biológicos como a FA possam ser usados para tomar decisões terapêuticas importantes. Embora a ultrassonografia tenha se estabelecido como uma técnica confiável para o diagnóstico precoce da cicatrização de fraturas agudas, seu papel na avaliação dos resultados do tratamento da ausência de consolidação ainda não foi determinado. Enquanto radiografias pontuais dão informações qualitativas sobre alterações durante a consolidação da fratura, os achados dos níveis de FA e da ultrassonografia, isoladamente, não têm limites laboratoriais definidos para o período de acompanhamento após a fixação que possam ser utilizados na diferenciação de casos favoráveis e desfavoráveis. Além disso, a ultrassonografia requer treinamento e conhecimento técnico para a demonstração dos resultados necessários. Isso pode limitar o uso generalizado da ultrassonografia nesses casos. Embora o equipamento possa ser adquirido com facilidade, nem todas as instituições contam com profissionais treinados para avaliar o processo de cicatrização. Além disso, um estudo sobre o custo-benefício da ultrassonografia poderia validar ainda mais o papel dessa técnica no monitoramento da consolidação de fraturas. A radiografia simples convencional certamente continuará a ser um método popular de avaliação devido à sua longa história comprovada, praticidade, e custos menores. ${ }^{1,18}$

\section{Conclusão}

O tamanho limitado da amostra deste estudo excluiu qualquer conclusão estatística. Mudanças significativas sugestivas de consolidação foram simultaneamente observadas em radiografias, ultrassonografias e níveis de FA durante o período de acompanhamento. $O$ primeiro ponto em que a concentração de FA e a ultrassonografia previram um possível resultado do tratamento coincidiu com as primeiras mudanças observadas nas radiografias. No entanto, a avaliação seriada dos níveis de FA e a ultrassonografia indicaram o progresso do tratamento. No momento, seu papel no monitoramento do resultado da ausência de consolidação é mais complementar do que suplementar à radiografia.

\section{Suporte Financeiro}

Não houve suporte financeiro de fontes públicas, comerciais, ou sem fins lucrativos.

\section{Conflito de Interesses}

Os autores declaram não haver conflito de interesses.

\section{Referências}

1 Nandra R, Grover L, Porter K. Fracture non-union epidemiology and treatment. Trauma 2016;18(01):3-11

2 Wawrzyk M, Sokal J, Andrzejewska E, Przewratil P. The role of ultrasound imaging of callus formation in the treatment of long bone fractures in children. Pol J Radiol 2015;80:473-478

3 Zimmermann G, Müller U, Wentzensen A. The value of laboratory and imaging studies in the evaluation of long-bone non-unions. [published correction appears in Injury. 2007;38(10):1224]Injury 2007;38(Suppl 2):S33-S37

4 Taniguchi T, Matsumoto T, Shindo H. Changes of serum levels of osteocalcin, alkaline phosphatase, IGF-I and IGF-binding protein3 during fracture healing. Injury 2003;34(07):477-479

5 Ajai S, Sabir A, Mahdi AA, Srivastava RN. Evaluation of serum alkaline phosphatase as a biomarker of healing process progression of simple diaphyseal fractures in adult patients. Int Res J Biol Sci 2013;2:40-43

6 Nilsson BE, Westlin NE. The plasma concentration of alkaline phosphatase, phosphorus and calcium following femoral neck fracture. Acta Orthop Scand 1972;43(06):504-510

7 Muljačić A, Poljak-Guberina R, Turčić J, Živković O, Guberina M, Klaić B The changes of bone-specific alkaline phosphatase (BALP) associated with callus formation and rate of bone healing. Croat Chem Acta 2010;83(03):315-321

8 Das S, Ghosh S, Pal K, Chaudhuri A, Datta S. Changes in biochemical markers in blood and urine in case of malunion and nonunion after fracture of long bones. Saudi J Sports Med 2015;15 (03):269-275

9 Emami A, Larsson A, Petrén-Mallmin M, Larsson S. Serum bone markers after intramedullary fixed tibial fractures. Clin Orthop Relat Res 1999;(368):220-229

10 Oni OO, Mahabir JP, Iqbal SJ, Gregg PJ. Serum osteocalcin and total alkaline phosphatase levels as prognostic indicators in tibial shaft fractures. Injury 1989;20(01):37-38

11 Bowles SA, Kurdy N, Davis AM, France MW, Marsh DR. Serum osteocalcin, total and bone-specific alkaline phosphatase following isolated tibial shaft fracture. Ann Clin Biochem 1996;33(Pt 3):196-200

12 Kachewar SG, Kulkarni DS. Utility of diagnostic ultrasound in evaluating fracture healing. J Clin Diagn Res 2014;8(03):179-180

13 Craig JG, Jacobson JA, Moed BR. Ultrasound of fracture and bone healing. Radiol Clin North Am 1999;37(04):737-751

14 Moed BR, Kim EC, van Holsbeeck M, et al. Ultrasound for the early diagnosis of tibial fracture healing after static interlocked nailing without reaming: histologic correlation using a canine model. J Orthop Trauma 1998;12(03):200-205

15 Allen GM, Wilson DJ. Ultrasound and the diagnosis of orthopaedic disorders. J Bone Joint Surg Br 1999;81(06):944-951

16 Moed BR, Subramanian S, van Holsbeeck M, et al. Ultrasound for the early diagnosis of tibial fracture healing after static interlocked nailing without reaming: clinical results. J Orthop Trauma 1998;12(03):206-213

17 Cunningham JL, Kenwright J, Kershaw CJ. Biomechanical measurement of fracture healing. J Med Eng Technol 1990;14(03):92-101

18 Chachan S, Tudu B, Sahu B. Ultrasound monitoring of fracture healing: is this the end of radiography in fracture follow-ups? J Orthop Trauma 2015;29(03):e133-e138

19 Sun MH, Leung KS, Zheng YP, et al. Three-dimensional high frequency power Doppler ultrasonography for the assessment of microvasculature during fracture healing in a rat model. J Orthop Res 2012;30(01):137-143 